\section{JURNAL ABDIMAS

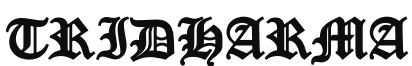

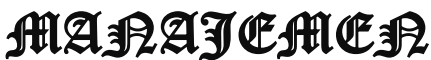

ISSN 2715-7105, E-ISSN 2716-070X

rnal ABDIMAS Vol. 2, No. 1, Januari 2021,Hal (90-95)

'rodi Manajemen Fakultas Ekonomi Universitas Pamulang

ail: abdimasjurnal.unpam@ gmail.com Telp: (021) 741-2566

\title{
PELATIHAN PEMAHAMAN PENTINGNYA E-COMMERCE DALAM TEKNIK PEMASARAN BERWIRAUSAHA
}

\author{
Eko Sudarso, Moh. Jazuli, Budhi Prabowo, Rio Setiawan, Whina Ratnawati \\ Dosen Fakultas Ekonomi Universitas Pamulang \\ E-mail : dosen02070@unpam.ac.id, dosen01680@unpam.ac.id, \\ dosen02034@unpam.ac.id, dosen02059@unpam.ac.id, dosen02057@unpam.ac.id
}

\begin{abstract}
ABSTRAK
Perdagangan dengan melalui media Elektronik adalah aktivitas penyebaran, penjualan, pembelian, pemasaran produk (barang dan jasa), dengan memanfaatkan jaringan internet. Adapun tujuan dari Pengabdian kepada Masyarakat (PKM) ini adalah untuk menanamkan pemahaman bagaimana manajemen pemasaran yang efektif bagi usaha kecil dan mikro; mengetahui peran usaha kecil dan mikro dalam pemasaran online serta menanamkan pemahaman bagaimana pemasaran berbasis online efektif melalui disiplin ilmu yang benar di Rumah Yatim, Al-Amiin Ciater, Kota Tangerang Selatan.

Dalam melaksanakan kegiatan PKM digunakan beberapa meode pelatihan, yaitu: 1) Metode Ceramah/Presentasi. Metode ceramah/presentasi dipilih untuk memberikan penjelasan tentang: a. Memberikan pengetahuan terkait pemasaran online. b. Presentasi mengenai materi e-commerce; 2) Metode Tanya Jawab. Metode tanya jawab sangat penting bagi para peserta pelatihan. Metode ini memungkinkan menggali pengetahuan sebanyak-banyaknya tentang pengelolaan pemasaran online; 3) Sharing Session Tentang mengoptimalkan pemasaran melalui online. Sharing session ini diberikan kepada para peserta pelatihan dalam memberikan masukan dan bimbingan untuk mempraktekan materi yang diperoleh. Harapannya, peserta pelatihan dapat menguasai materi pelatihan yang diterima dan dapat diaplikasikan dalam mengelola usahanya.

Adapun hasil dari kegiatan Pengabdian kepada Masyarakat ini adalah pengenalan manajemen pemasaran berbasis online usaha mikro pada Kelurahan Rempoa. Dengan cara manajemen yang benar dalam pemasara online dengan media E-commerce dapat meningkatkan keuntungan dengan memperhatikan produk yang akan dijualnya melalui media online.
\end{abstract}

\section{Kata Kunci: Manajemen Pemasaran, E-commerce}

\section{ABSTRACT}

Digital trade is the expansion, sale, purchase, and marketing of the product (goods and services) that utilize an internet network. The purpose of these community services is to raise the understanding of how marketing management effectiveness for small and medium enterprises; knowing the small and medium enterprise roles in digital marketing also develops the knowledge of effective digital marketing using appropriate knowledge discipline in Rumah Yatim Al-Amin Ciater, Kota Tangerang Selatan.

Coaching methods in these Comunity Services combine several approaches; 1) Presentation. The presentation describes a. knowledge regarding online marketing, b. e- 


\section{JURNAL ABDIMAS

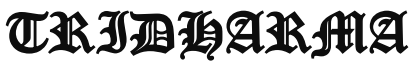 HA:}

ISSN 2715-7105, E-ISSN 2716-070X

rnal ABDIMAS Vol. 2, No. 1, Januari 2021,Hal (90-95)

'rodi Manajemen Fakultas Ekonomi Universitas Pamulang

ail: abdimasjurnal.unpam@ gmail.com Telp: (021) 741-2566

commerce materials. 2) Question and Answer. The Question and Answer are essential for the coaching participants. This method enables participants to collect significant knowledge regarding digital marketing. 3) Sharing Session regarding optimizing marketing using the digital platform. The sharing session present to the participants in order to give feedback and direction to apply the knowledge. Coaching participants expected able to perceive and apply the coaching material to manage their business.

As a result of the Community Services, marketing management is introduced based on the online platform in micro-enterprise on Rempoa sub-district. With appropriate management in digital marketing using E-commerce, able to increase the profit by considering the product to sell on the online platform.

\section{Key Words: Marketing Management, E-Commerce}

\section{PENDAHULUAN}

Salah satu media komunikasi yang dapat digunakan pelaku usaha untuk mempromosikan usahanya adalah komunikasi media maya atau media internet. Pelaku Usaha Kecil dan Mikro (UKM) dapat memanfaatkan e-commerce dan marketplace yang memberikan peluang yang besar untuk bisa mengekspansi penjualan produk mereka melalui media digital. Pelaku UKM perlu memanfaatkan bermacam cara untuk melakukan promosi dan meningkatkan penjualan produk mereka, salah satunya dengan memanfaatkan peluang yang ada.

Namun,berdasarkan data yang dirilis oleh Kementrian Koperasi dan Usaha Kecil Menengah (Kemenkop UKM), baru sekitar 3.79 juta pelaku UKM yang sudah memanfaatkan platform online dalam memasarkan produknya. Jumlah ini berkisar 8 persen dari total pelaku UKM di Indonesia, yaitu 59.2 juta (www.cnnindonesia.com).

Pertumbuhan industri e-Commerce Indonesia diprediksi mencapai sebesar US\$ 130 miliar pada tahun 2020. Pertumbuhan industri e-commerce per tahun yang mencapai 50 persen ditambah dengan pengguna smartphone yang terus bertumbuh merupakan peluang yang sangat besar untuk pelaku UKM dalam meningkatkan penjualan produk mereka. $\begin{array}{cccc}\text { Salah satu penelitian } & \text { yang } \\ \text { dilakukan oleh } & \text { Pradiani } & \text { (2018) }\end{array}$ menunjukkan bahwa Ibu-ibu PKK sangat merasakan begitu besar manfaat yang diperoleh dengan menggunakan sosial media sebagai sarana kegiatan pemasaran hasil industri rumahannya. Hal ini mengindikasikan bahwa digital marketing sangat potensial untuk dikembangkan. Pelaku UKM dapat memanfaatkan media sosial untuk mempromosikan produknya. Sejalan dengan pernyataan Moriansyah (2015) berdasarkan alasan atau motivasi pemasar menggunakan media sosial (antecedants) dan target dari progam pemasaran (consequences) yang dapat diraih dengan menggunakan media sosial.

Pelanggan akan mendapatkan stimulus dari promosi yang dilakukan pemasar, keluarga, teman, atau komonitas online, untuk menjadi aktif shopping. Stimulus tersebut dapat datang terus menerus di dalam media sosial. Implakasi pemasar terhadap evolusi tersebut adalah brand harus dapat menyebar dan fleksibel, brand harus membangun komunikasi dengan pelanggan dan calon pelanggan. Digital marketing memungkinkan pembeli memperoleh seluruh informasi mengenai produk dan bertransaksi melalui internet, dan memungkinkan penjual memantau dan menyediakan kebutuhan serta keinginan calon pembeli tanpa batasan waktu dan geografis. Kelurahan Ciater, Tangerang Selatan adalah kota dengan pelaku UKM 


\section{JURNAL ABDIMAS

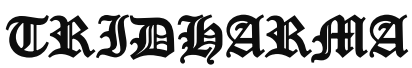

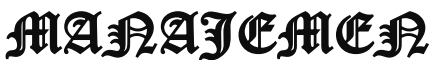

ISSN 2715-7105, E-ISSN 2716-070X

rnal ABDIMAS Vol. 2, No. 1, Januari 2021,Hal (90-95)

'rodi Manajemen Fakultas Ekonomi Universitas Pamulang

ail: abdimasjurnal.unpam@ gmail.com Telp: (021) 741-2566 potensial di Propinsi Banten. Hingga tahun 2020 ini belum ada data yang menunjukkan pelaku UKM di kelurahan Ciater yang menerapkan e-commerce untuk menjual produk yang dihasilkan. Ini menjadi salah satu hal yang patut diperhatikan ditengah kemajuan dalam bidang pemasaran. Media promosi konvensional hendaknya dapat berkolaborasi dengan media digital, sehingga pelaku UKM lebih maksimal dalam memasarkan produk.

Berdasarkan penelusuran yang dilakukan, didapatkan fakta bahwa masih sangat minim pelaku UKM yang menggunakan digital marketing. Hal tersebut terjadi karena tidak adanya pengetahuan dari pelaku UKM mengenai digital marketing. Permasalahan ini dapat diatasi dengan memberikan pengetahuan tentang pentingnya penguasaan digital marketing dalam dunia usaha. Sementara itu APJII (Asosiasi Penyelenggara Jasa Internet Indonesia) merilis data yang menujukkan bahwa telah terjadi peningkatan angka pertumbuhan pengguna internet setiap tahunnya. Bertambahnya angka pengguna internet merupakan potensi besar bagi pelaku UKM untuk memanfaatkan platform penjualan melalui dunia maya. Sehingga pelaku UKM dapat melakukan ekspansi bisnis melalui kegiatan offline maupun online.

Media promosi digital diharapkan menjadi pilihan yang efektif untuk pelaku UKM dalam mengembangkan bisnis dan menjangkau pasar nasional maupun internasional. Media promosi konvensional yang banyak membutuhkan biaya dan jauh lebih rumit dengan sendirinya tidak lagi menjadi perhatian utama bagi pelaku UKM karena adanya digital marketing. Pelaku $\mathrm{UKM}$, dengan menggunakan e-commerce atau marketplace dapat menjangkau calon costumer yang lebih luas dan lebih banyak, tidak hanya terbatas pada suatu wilayah promosi saja.

Digital marketing dan e-commerce atau marketplace dapat menjangkau wilayah yang lebih luas dibanding pemasaran secara konvensional, sehingga hal ini menjadi pilihan yang solutif untuk ekspansi bisnis. Pelatihan ini sasarannya adalah pelaku UKM yang berada di kelurahan Ciater, Tangerang Selatan. Pada pelatihan ini bertujuan untuk memberikan edukasi kepada pelaku UKM tentang digital marketing dan bagaimana menggunakan $e$ commerce atau marketplace.

\section{RUMUSAN MASALAH}

Adapun rumusan masalah dalam PKM ini adalah:

1. Bagaimana manajemen pemasaran yang efektif di Di Rumah Yatim Al-Amiin, Ciater, Kota Tangerang Selatan?

2. Bagaimana peran usaha kecil dan mikro di Di Rumah Yatim Al-Amiin, Ciater, Kota Tangerang Selatan?

3. Bagaimana manajemen pemasaran berbasis online untuk usaha kecil dan mikro?

\section{TUJUAN PELAKSANAAN}

ini adalah:

Adapun tujuan dari kegiatan PKM

1. Untuk menanamkan pemahaman bagaimana manajemen pemasaran yang efektif bagi usaha kecil dan mikro;

2. Untuk mengetahui peran usaha kecil dan mikro dalam pemasaran online;

3. Untuk menanamkan pemahaman bagaimana pemasaran berbasis online efektif melalui disiplin ilmu yang benar

\section{TINJAUAN PUSTAKA}

\section{Pengertian E-commerce}

\section{E-commerce (Elektronik}

Commerce) atau dalam bahasa indonesia Perdagangan Secara Elektronik adalah aktivitas penyebaran, penjualan, pembelian, pemasaran produk (barang dan jasa), dengan memanfaatkan jaringan 


\section{JURNAL ABDIMAS

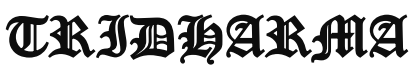

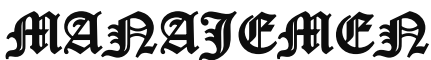

ISSN 2715-7105, E-ISSN 2716-070X

rnal ABDIMAS Vol. 2, No. 1, Januari 2021,Hal (90-95)

'rodi Manajemen Fakultas Ekonomi Universitas Pamulang

ail: abdimasjurnal.unpam@ gmail.com Telp: (021) 741-2566 telekomunikasi seperti internet, televisi, atau jaringan komputer lainnya. Secara sederhana e-commerce adalah proses pembelian maupun penjualan produk secara elektronik. e-commerce sendiri semakin berkembang beberapa tahun belakangan ini dan secara perlahap menggantikan toko tradisional (Offline).

Perdagangan elektronik (bahasa Inggris: electronic commerce atau $e$ commerce adalah penyebaran, pembelian, penjualan, pemasaran barang, dan jasa melalui sistem elektronik seperti internet atau televisi, www, atau jaringan komputer lainnya. E-commerce dapat melibatkan transfer dana elektronik, pertukaran data elektronik, sistem manajemen inventori otomatis, dan sistem pengumpulan data otomatis

Industri teknologi informasi melihat kegiatan e-commerce ini sebagai aplikasi dan penerapan dari e-bisnis (ebusiness) yang berkaitan dengan transaksi komersial, seperti: transfer dana secara elektronik, SCM (supply chain management), pemasaran elektronik ( $e$ marketing), atau pemasaran online (online marketing), pemrosesan transaksi online (online transaction processing), pertukaran data elektronik (electronic data interchange /EDI), dll.

E-commerce merupakan bagian dari e-business, di mana cakupan e-business lebih luas, tidak hanya sekadar perniagaan tetapi mencakup juga pengkolaborasian mitra bisnis, pelayanan nasabah, lowongan pekerjaan dll. Selain teknologi jaringan www, e-commerce juga memerlukan teknologi basisdata atau pangkalan

data (databases), surat elektronik (e-mail), dan bentuk teknologi non komputer yang lain seperti halnya sistem pengiriman barang, dan alat pembayaran untuk edagang ini

\section{METODE PELAKSANAAN}

Metode pelaksanaan pengabdian ini dilakukan dalam beberapa kegiatan yaitu tahap survei yaitu sosialisasi dilakukan dengan menyusun berbagai hal yang akan disampaikan pada saat kegiatan pengabdian yang akan dilakukan yang meliputi: penyusunan materi yang akan diberikan, penyusunan jadwal pemberian materi, pembagian tugas tim pengabdian dan survei ke lokasi pengabdian. Tahap sosialisasi yaitu sebelum kegiatan pengabdian dilaksanakan terlebih dahulu dilakukan tahap sosialisasi yaitu melakukan silaturahmi dengan kepala kelurahan dan ketua ikatan pedagang yang ada di sekitar kelurahan Rempoa, menyampaikan maksud dan tujuan pengabdian ini. Pada tahap ini juga dilakukan jalinan kerjasama dan menentukan jadwal kegiatan pengabdian. Tim pelaksana kegiatan pengabdian pada masyarakat adalah dosen Fakultas Ekonomi jurusan manajemen sebanyak 5 orang. Tim pengabdian memberikan materi tentang pemasaran online di di kelurahan Rempoa, Ciputat, Tangerang Selatan dan akan memberikan pelatihan disana.

\section{HASIL DAN PEMBAHASAN}

Pengabdian Masyarakat (LPPM) Universitas Pamulang yang dilakukan oleh dosen-dosen program studi Manajemen telah berjalan dengan lancar dan mendapat sambutan hangat dari tempat pelaksanaan kegiatan ini yaitu kelurahan Rempoa, Ciputat, Tangerang Selatan

Harapan kami dengan pengabdian ini dapat membuka wawasan para UKM menngenai pemasaran online yang akan meningkatkan penjualan mereka. Materi yang kami berikan yaitu pembelajaran dan praktek dalam bidang digital marketing khususnya e-commerse dan media sosial yang baik sekaligus bahan kajian dan masukan bagi para pelaku UMKM tersebut untuk dapat mengimplementasikannya dalam kehidupan sehari-hari, sehingga dapat membantu dan meningkatkan tingkat keilmuan yang akan sangat bermanfaat dalam kehidupan mereka pada masa yang akan datang. 


\section{JURNAL ABDIMAS

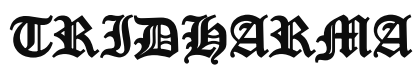

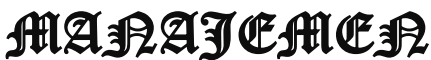

ISSN 2715-7105, E-ISSN 2716-070X

rnal ABDIMAS Vol. 2, No. 1, Januari 2021,Hal (90-95)

'rodi Manajemen Fakultas Ekonomi Universitas Pamulang

ail: abdimasjurnal.unpam@ gmail.com Telp: (021) 741-2566

\section{KESIMPULAN DAN SARAN}

\section{Kesimpulan}

Peserta kurang mengerti apa itu pemasaran online. Peserta juga belum mengetahui bagaimana memulai mempromosikan usahanya secara online.

\section{Saran}

Setelah pengabdian ini diharapkan peserta dapat memiliki pengetahuan bagaiman cara mempromosikan usahanya secara online. Tim pengabdian agar terus melakukan kegiatan-kegiatan serupa secara berkesinambungan di masa yang akan datang

\section{DAFTAR PUSTAKA}

La Moriansyah. 2015. Pemasaran Melalui Media Sosial: Antecendents dan Consequences. Jakarta: Jurnal Penelitian Komunikasi dan Opini Publik Vol 19, No 3.

Pasaribu, V. L. D., Susanti, F., \& Hartuti, E. T. K. (2019). Memotivasi Siswa dan Siswi SMK Letris Indonesia di Dalam Menentukan Pilihan Untuk Melanjutkan Pendidikan Atau Bekerja Setelah Lulus Sekolah. Jurnal Pengabdian Dharma Laksana, 1(2), 161-172.

Pasaribu, V. L. D., Agrasadya, A., Shabrina, N., \& Krisnaldy, K. (2020). MENJADI ENTERPRENEUR MUDA YANG MEMILIKI JIWA LEADERSHIP UNTUK MENGHADAPI MASA DEPAN. Abdi Laksana, 1(1).

Pasaribu, V. L. D., Elburdah, R. P., Sudarso, E., \& Fauziah, G. (2020). PENGGUNAAN MANAJEMEN WAKTU TERHADAP PENINGKATAN PRESTASI BELAJAR DI SMP ARAISIYAH. Jurnal ABDIMAS Tri Dharma Manajemen, 1(1).

Pasaribu, V. L. D., Sulaiman, S., Sutiman, S., Thaharudin, T., \& Purnomo, B. Y.

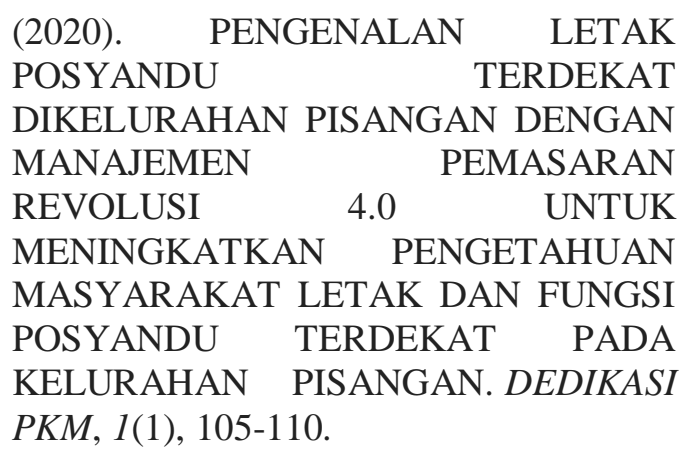

Pasaribu, V. L. D., Oktrima, B., Prabowo, B., Arianto, N., \& Haryoko, U. B. (2020). PROGAM PENDAMPINGAN DAN PENYELENGGARAAN PENDIDIKAN ANAK PADA USIA DINI TERHADAP PRESTASI BELAJAR DILINGKUNGAN RT 020 RW 009. KEL GIRI PENI. KEC WATES. YOGYAKARTA. JURNAL LOKABMAS KREATIF, 1(1), 71-75.

Pradiani, Theresia. 2018. Pengaruh Sistem Pemasaran Digital Marketing Terhadap Peningkatan Volume Penjualan Hasil Industri Rumahan. Malang: Jurnal Ilmiah Bisnis dan Ekonomi Asia Vol. 11 No. 2. ---. 2020. Pelaku UKM yang Memanfaatkan Platform Online. Jakarta: www.cnnindonesia.com.

\section{DOKUMENTASI FOTO KEGIATAN}

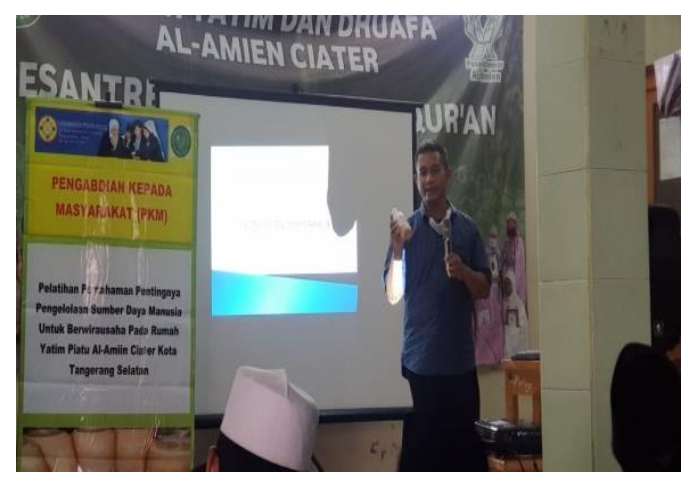


JURNAL ABDIMAS

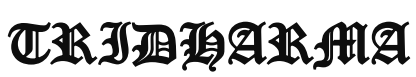

AIA
ISSN 2715-7105, E-ISSN 2716-070X

rnal ABDIMAS Vol. 2, No. 1, Januari 2021,Hal (90-95)

'rodi Manajemen Fakultas Ekonomi Universitas Pamulang

ail: abdimasjurnal.unpam@ gmail.com Telp: (021) 741-2566
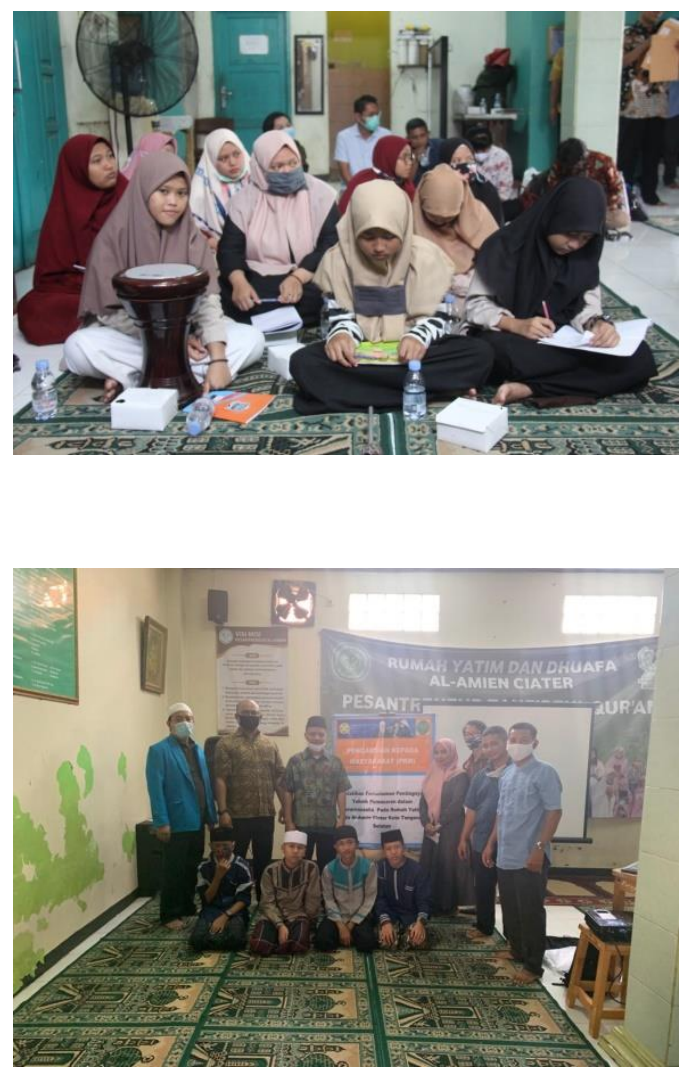